\title{
As potencialidades do filme "procurando Dory" para o ensino de ciências e biologia
}

\author{
The potentialities of the film "finding Dory" for science and biology \\ teaching
}

Lucas de Esquivel Dias Brandão ${ }^{1}$

Roberta Rodrigues da Matta ${ }^{2}$

Marcelo Diniz Monteiro de Barros ${ }^{3}$

\begin{abstract}
Resumo
O presente estudo objetiva demonstrar o potencial pedagógico da utilização das personagens presentes na animação "Procurando Dory" para o ensino de Ciências e Biologia. O filme citado anteriormente foi escolhido, no presente estudo, já que apresenta relevantes aspectos relacionados com a vida marinha dos animais e que podem facilmente ser discutidos no ensino de Ciências e Biologia. Para isso, foram selecionados oito principais personagens presentes na animação, a saber: Dory, Marlyn, Nemo, Tio Raia, Crush, Hank, Destiny e Bailey. Com o material apresentado nesse estudo os professores de Ciências e Biologia podem discutir variados conteúdos com seus alunos, como por exemplo: Morfologia, Alimentação, Distribuição geográfica, Aspectos antropológicos, Relações ecológicas, Reprodução, Características biológicas e Habitat, dos principais personagens existentes no filme. Espera-se que os professores de Ciências e Biologia tenham acesso a essa atividade e que possam, de acordo com os seus anseios, trabalhar as diferentes características biológicas que se fazem presentes nos personagens aqui exibidos.
\end{abstract}

Palavras-chave: Animação. Procurando Dory. Filme como estratégia de Ensino. Ensino de Ciências e de Biologia.

\section{Abstract}

The present study aimed to demonstrate the pedagogical potential of using the characters present in the animation "Finding Dory" (2016) for Science and Biology teaching. The previously mentioned film was chosen, in the present study, since it presents relevant aspects related to the marine life of

\footnotetext{
${ }^{1} \mathrm{O}$ autor é mestrando no Programa de Pós Graduação em Biologia de Vertebrados da PUC Minas. E-mail: lucasdesquivel@hotmail.com

${ }^{2}$ A autora é Docente na Prefeitura Municipal de Itaguaí (RJ) e Mestre em Ciência, Tecnologia e Educação pelo CEFET/RJ.E-mail: beta_matta@hotmail.com

${ }^{3} \mathrm{O}$ autor é Doutor em Ensino em Biociências e Saúde pelo Instituto Oswaldo Cruz - Fiocruz e Professor Adjunto IV do Departamento de Ciências Biológicas da Pontifícia Universidade Católica de Minas Gerais e Professor Colaborador do Programa de Pós-Graduação em Ensino em Biociências e Saúde (PG-EBS) pelo Instituto Oswaldo Cruz - Fiocruz Laboratório de Inovações em Terapias, Ensino e Bioprodutos (LITEB). E-mail: marcelodiniz@pucminas.br
} 
the animals and that can easily be discussed in the Science and Biology teaching. For this, we selected eight main characters present in the animation, namely: Dory, Marlyn, Nemo, Uncle Ray, Crush, Hank, Destiny and Bailey. With the material presented in this study, Science and Biology teachers can discuss varied contents with their students, such as: Morphology, Feeding, Geographical distribution, Anthropological aspects, Ecological relationships, Reproduction, Biological characteristics and Habitat, of the main characters presented in the film. It is hoped that Science and Biology teachers have access to this activity and, can according to their desires, work the different biological characteristics presents in the characters here shown.

Key-words: Animation. Finding Dory. Film as a teaching strategy. Science teaching. Biology teaching.

\section{INTRODUÇÃO}

\subsection{Um breve histórico do cinema de animação}

Em 1645, Athanasius Kircher expôs ao público a "lanterna mágica", nada mais que uma caixa portadora de fonte de luz e de um espelho curvo, através do qual projetava-se imagens, derivadas de lâminas de vidros pintadas. Mais tarde, no século XVIII, Pieter Van Musschenbroek, continuando os estudos de Kircher, consegue produzir a ilusão de movimento, em 1736, ano esse da primeira exibição animada. Esse modelo foi então se popularizando como veículo de entretenimento até que em 1794, Etienne Gaspard Robert, em Paris, explorou de forma comercial o grande potencial que a "lanterna mágica" possuía, no espetáculo Fantasmagorie (LUCENAJÚNIOR, 2001).

Os estudos sobre a ilusão de ótica continuaram a ser desenvolvidos, permitindo inovações e aprimoramentos no formato. Um importante artigo foi publicado em 1826 por Peter Mark Roget, em que definiu que o olho humano percebe imagens sequenciais como um único movimento. Esse importante achado desencadeou uma série de 
invenções direcionadas à impressão do movimento. Em 1825 surge o "taumatroscópio", para servir de ferramenta para a animação. Composto de um disco suspenso por cordões munidos de imagens, na parte frontal e no verso, permitia, quando girados, a fusão das imagens, dando a impressão de mobilidade. Entre os anos de 1828 e 1832, Joseph Plateau inventou o "fenaquistoscópio", mecanismo capaz de apresentar a animação de desenhos. Este aparelho consistia em dois discos com sequências de imagens pintadas que, quando simultaneamente girados, sugeriam movimento. Similar a esse, mas dotado de um único disco, Simon Von Stampfer trouxe a público o "estroboscópio" (MORRISON, 1994).

Em 1834, surgiu o "zootroscópio", criado por William Horner, seguindo os mesmos princípios das criações anteriores. Nesse aparelho os desenhos eram dispostos em um tambor, espaçados por pequenas frestas, as quais permitiam a sensação de movimento. Em 1868, o flip book (livro mágico) conquistou grande repercussão, sendo considerado pelos primeiros animadores como um instrumento inspirador de sequências narrativas. Uma impressão de ação filmica era transmitida através dos desenhos dispostos em cada página do livro, quando rapidamente transpostas (FOSSATTI, 2009).

O "praxinoscópio" foi criado em 1877 por Emile Reynaud. O aparelho constituia-se por um sistema de espelhos e lentes, as figuras eram projetadas sobre a tela, criando a base da tecnologia do cinema. Foi através desse recurso que, Reynaud em 1892, criou seu Teatro Óptico (LUCENA-JÚNIOR, 2001).

Portanto, entende-se que a animação revela-se mais antiga que o próprio cinema (FOSSATTI, 2009), criado pelos irmãos Lumière em 1895, quando da primeira apresentação com o cinematógrafo em Paris (aparelho utilizado tanto para filmar quanto para projetar). Esse se 
estabeleceu como a primeira exibição pública de filmes bem curtos, em preto e branco e sem som (PINTO, 2004).

Em 1878, Eaweard James Muybridge criou brinquedos ópticos como o Zootrópio e o Thaumatrópio os quais davam uma ilusão de movimento. Tais brinquedos tornaram-se os precursores do cinema (DOURADO-JUNIOR, 2007).

A invenção da fotografia, associada à técnica do praxinoscópio, bem como os estudos de fisiologia dos movimentos humanos e animais, do médico francês Etiènne Jules Marey, tornaram-se referência para animadores. Etiènne Marey desenvolveu e aprimorou uma câmera para o registro de movimentos rápidos. A tudo isso foram acrescentadas novas descobertas, que atingiram o cume com os irmãos Lumière, através do cinematógrafo (FOSSATTI, 2009).

"Humorous Phases of Funny Faces", um filme produzido por Stuart Blackton, em 1906, é considerado o primeiro filme animado produzido (NOWELL-SMITH, 1996). Em 1908, Emile Cohl produziu a animação Fantasmagorie. Essa produção foi a precursora dentre os desenhos animados que se valeram integralmente da técnica frame by frame, apresentando movimentos dotados de fluidez. Posteriormente, Winsor McCay, em 1914, concluía a produção do curta-metragem "Gertie, the Dinosaur", marco na história da animação, para o qual foram utilizados aproximadamente 10 mil desenhos (A EVOLUÇÃO..., 2004).

$\mathrm{O}$ início do século XX demarcou o nascimento das salas de cinema, em cujas telas o Gato Félix, Betty Boop e Mickey ganhavam visibilidade (CANEMAKER, 1991; GUILÉN, 1997). O Boom da animação ocorreu entre os anos de 1910 e 1940, período em que a mesma passava por um intenso processo de industrialização. A exigência de prazos e os altos custos das produções estimulavam os 
artistas a desenvolverem incessantemente novas técnicas. A rotoscopia e o acetato, caracterizado pelo desenho sobre o celuloide transparente, emergiam como novos recursos ao formato, oferecendo novas possibilidades à animação tradicional. Por meio do acetato, apresentado por Earl Hurd, pôde-se desvincular o personagem de seu cenário. Agora os autores podem destinar uma maior atenção plástica aos personagens, pois a fotografia foi quem passou a ser utilizada como cenário. Os idealizadores de Popeye, Betty Boop e o palhaço Koko, criaram em 1915 a rotoscopia. Por fim, essas invenções mais uma vez buscavam aprimorar os movimentos, recobrindo-lhes de realismo e oportunizando novas possibilidades para a animação, ampliando dessa maneira seu mercado (LUCENA-JÚNIOR, 2001).

Em 1921 a animação elástica emergia como novo procedimento estético. Esse recurso libertava o artista da aplicação dos limites humanos a seus personagens, os quais agora eram capazes de esticar e encolher, adaptando-se a inúmeras formas. Foi nesse momento que o Gato Félix, criado por Otto Messmer, em 1900, ganhava popularidade (FOSSATTI, 2009).

Oskar Fichinger destacou-se em 1930 na Alemanha por ter associado imagens abstratas com a sonoridade. Suas criações surrealistas inspiraram o longa-metragem de Walt Disney "Fantasia", em 1940 (RUSSETT; STARR, 1988).

Norman McLaren conquistava visibilidade nesse período, já que foi o precursor dos filmes em três dimensões através da utilização do estereoscópio, ferramenta de sua própria invenção. Nessa técnica, os desenhos eram fotografados quadro a quadro $\mathrm{e}$ exibidos alternadamente por dois projetores. Inicialmente essa técnica gerou grande encanto, mas logo outras possibilidades surgiram (RICHARD, 1982). Encorajados por McLaren, métodos em celuloides, areia, óleo em vidro, e pincel, foram amplamente utilizados e experimentados 
pelos mais diversos animadores. Simultaneamente Walt Disney começava a ganhar visibilidade, tornando-se fenômeno mundial e determinando o caminho pelo qual a animação iria se dirigir (THOMAS; JOHNSTON, 1995).

O personagem comercializado pela Universal Studios chamado "Oswald: the lucky rabbit" foi o precursor das animações da Disney. Entre os anos de 1927 a 1928, foram lançados aproximadamente 28 curtas metragens para esse estúdio (ELIOT, 1993). Nessa época Walt Disney retomou seu projeto de trabalhar com o Mickey Mouse, criado por Ub Iwerks, porém não alcançou a mesma aceitação que Oswald the lucky rabbit. Em 1928, a animação "Mickey o navegador" alcançou notoriedade, sendo reconhecida como a precursora da animação sonora (THOMAS, 1969).

Em 1937, com as possibilidades oferecidas pela câmera de múltiplos planos, a Disney conseguiu efeitos tridimensionais representados, por exemplo, em a "Branca de Neve e os sete anões" (THOMAS, 1969).

Em 1940 o personagem Mickey retorna em "Aprendiz de feiticeiro". Pela primeira vez, essa cinematografia combinava música erudita com desenhos animados, em uma sinfonia de cores, formas e sons. Em 1941 com "Dumbo" inaugurou-se alguns princípios surrealistas, marcados por abusos ilógicos. Em 1950, a United Productions of America (UPA) revelou "Cinderela", seguido de "Alice no país das maravilhas" no ano seguinte, e Peter Pan em 1953. Em 1955 lançou o primeiro filme a utilizar o cinemascope, fato que obrigou a companhia a construir uma miniatura detalhada de todos os cenários do filme.

No ano de 1959 a Disney lança "A bela adormecida", que foi o primeiro desenho de animação realizado em setenta milimetros, da mesma maneira que as superproduções com atores eram feitas. E 
também, caracterizou-se por ser o último filme desenhado inteiramente a mão (GUILLÉN, 1997). Em 1961 o primeiro filme a usar fotocopiadora foi "101 Dálmatas". E em 1967 "Mogli, o menino lobo" consagrou-se como a última grande produção agraciada pela participação de Walt Disney (1901-1966).

Mesmo em menor proporção, os estúdios Disney continuaram investindo no cinema de animação. Mas o ano de Ouro dos estúdios Disney se deu em 1989, com o lançamento de "A pequena Sereia", tendo seu ápice com "A bela e a fera" em 1991. Essa última animação foi um importante passo para a animação 3D, além de ser a primeira animação indicada ao Oscar na categoria de Melhor Filme. Este filme combinou a técnica clássica das animações Disney com as mais modernas conquistas da tecnologia digital existentes na época (FOSSATTI, 2009).

Em sequência, grandes sucessos foram lançados, como por exemplo, "Rei Leão" (1994). Novamente as técnicas tradicionais combinavam-se com aquelas advindas da tecnologia digital. A repercussão positiva desta produção fomentou a inserção massiva da tecnologia digital, culminando na primeira produção do gênero da animação totalmente digitalizada produzida pela Disney e Pixar, chamada "Toy Story" em 1995, que rendeu ao diretor Lasseter um Oscar especial por sua contribuição às Artes Cinematográficas.

Paralelamente a "Toy Story", aqui no Brasil finalizava-se em 1996 a produção de "Cassiopéia" (NDR), também totalmente digitalizada (D`ROSSI, 2002), ficando, portanto, em segundo lugar no ranking de pioneirismo das produções digitalizadas.

Os Estúdios Disney e Pixar, através de suas animações, tornaramse referência na animação $3 \mathrm{D}$. No entanto, gradualmente, essa hegemonia passou a ser ameaçada por outros estúdios, como a Dream 
Works Animation SKG e a 20 th Century Fox Animation, evidenciandose uma nova e acirrada disputa entre estúdios.

A Dream Works Animation SKG também inaugurou uma nova etapa do cinema de animação com a técnica de massa de modelar em "Fuga das Galinhas" (2000). Mas seu grande sucesso veio com "Shrek", momento que passou a ser uma das principais competidoras da Pixar/Disney (COELHO et al., 2004).

A 20 th Century Fox Animation fez parceria com a Blue Sky e alcançou, em 2002, o sucesso com o lançamento de "A era do gelo". Posteriormente, ganhando grande aceitação do público produziu-se "Procurando Nemo" (2003), “Os incriveis" (2004), e "Up: Altas aventuras" (2009), todos da Disney e Pixar.

\subsection{O cinema e sua relação com o Ensino de Ciências e Biologia}

O cinema, além de entretenimento, pode ser uma fonte de informação e conhecimento, já que os filmes funcionam como porta de acesso para conhecimentos e informações que não se esgotam. Além disso, conseguem retratar épocas, sociedades, aspectos culturais, políticos e econômicos (SOUZA et al., 2014).

O lúdico, quando utilizado pelo professor como estratégia de ensino, traz curiosidade, prende a atenção, instiga os alunos a se interessarem pelo que está sendo proposto, facilitando, portanto, a compreensão do conteúdo lecionado, deixando-os entretidos, curiosos e concentrados (SANTOS; SILVA, 2011).

O cinema vem sendo utilizado durante anos por educadores e autores como Araújo (1995) e Duarte (2002), que consideram os filmes importantes aliados para a construção do conhecimento. Através do contato quase que diário com os variados tipos de animação, professores podem pesquisar acerca do uso de métodos alternativos de 
ensino, como uma maneira de inovar em sala de aula e atrair a atenção de seus alunos (SANTOS, 2007).

Existem grupos de pesquisa que há algum tempo vem publicando trabalhos que demonstram as potencialidades que o cinema proporciona para o ensino de Ciências e Biologia, a saber: Barros, Girasole \& Zanella (2013), Souza et al. (2014), Barros \& Costa (2014), Costa \& Barros (2014), Campos et al. (2015), Nascimento et al. (2016), Campanini et al. (2016), Souza et al. (2016), Pin et al. (2016), Pereira e Barros (2017), Matta \& Barros (2017). Destacam ainda, a riqueza encontrada em cada filme, visto que diversas áreas do conhecimento podem ser contempladas e discutidas ao longo das cenas, o que nos parece ser uma oportunidade para discutir o ensino de forma interdisciplinar, além de despertar a utilização dos recursos audiovisuais também por parte dos professores das demais disciplinas, otimizando a utilização do tempo em sala de aula de forma criativa e contextualizada.

Cabe ressaltar que a prática de assistir filmes na escola de maneira direcionada e mediada pelo professor, destacando os aspectos relevantes e didáticos dos mesmos com os alunos, pode desenvolver nos estudantes uma visão mais ampla sobre os filmes de forma geral. E ainda, é possivel fazê-los perceber as diversas mensagens que um mesmo filme pode transmitir ao telespectador, a fim de contribuir para a formação de senso crítico nos alunos, como apontam Coelho e Viana (2011).

Diversos estudos foram publicados sobre o filme "Procurando Nemo" (2003), contextualizando o filme nas mais variadas áreas. Dentre elas, pode-se destacar na área de Letras o trabalho de Santos e Rodrigues (2014), sobre a análise do discurso dos personagens do filme, que teve como objetivo analisar o comportamento dos personagens do filme e relacioná-los com o tema inclusão social. Para 
a área das Ciências naturais existe o trabalho de Santos, Souza e Gebara (2015), que objetivou identificar fragmentos do enredo filmico que possibilitassem a construção de conceitos científicos de Biologia, Física e Química. No trabalho de Soares, Vieira e Fonseca (2014), foram observadas as percepções dos alunos, do $7^{\circ}$ ano do Ensino Fundamental, em relação aos conceitos biológicos e sociais presentes no filme "Procurando Nemo" e as possíveis formas de utilização do mesmo durante as aulas de Ciências.

Foi escolhido o filme Procurando Dory (2016) como foco do presente estudo, pois, até o presente momento, não detectou-se trabalhos que relacionam o filme "Procurando Dory" (continuação do procurando Nemo) com a Educação/Ensino, e também, pelo fato de que a animação apresenta relevantes aspectos relacionados com a vida marinha dos animais e que podem facilmente ser discutidos no ensino. Sendo assim, o presente estudo, contribuindo para aprimorar o ensino de Ciências e Biologia, objetivou discutir as características biológicas, como por exemplo, localização geográfica, alimentação, reprodução, morfologia e fisiologia das diferentes personagens existentes no filme "Procurando Dory" (2016). Espera-se que as discussões aqui instigadas sejam utilizadas por professores de Ciências e Biologia no Ensino Fundamental e Médio em seus mais variados contextos.

\subsection{O enredo do filme Procurando Dory (2016)}

Um ano após os eventos do filme Procurando Nemo (2003), Dory começa a ter sonhos e flashbacks de sua vida antes de conhecer Marlyn e Nemo. Após ouvir uma palestra sobre migração, em que animais marinhos usam o instinto para voltar para casa, algumas memórias de Dory são reativadas e ela tem a súbita vontade de encontrar seus pais, apenas vagamente lembrando que viviam na 
"Jewel of Morro Bay, na California". Marlyn é relutante em permitir que Dory viaje através do oceano, mas acaba concordando em deixá-la ir desde que acompanhe a mesma em sua missão.

Com a ajuda da tartaruga chamada Crush, Dory, Marlyn e Nemo vão para a Califórnia através de uma corrente oceânica. O trio acaba navegando por um naufrágio, local esse em que são forçados a fugir de uma Lula gigante predatória. Essa confusão toda acaba quase matando Nemo. Marlyn culpa a Dory por colocar o Nemo em tal situação e acaba, com raiva, brigando com a mesma. Dory começa a vagar pelo oceano e quando sobe para superficie acaba sendo, de repente, capturada por voluntários que trabalham perto de um Instituto de Vida Marinha.

No Instituto, Dory é marcada com uma etiqueta e enviada à seção de quarentena, onde conhece Hank, um fugitivo e mau humorado Polvo vermelho, de apenas sete tentáculos. Hank deseja a etiqueta de Dory, já que significa que em vez de ser lançado de volta na natureza como os outros peixes, ele será enviado para um aquário em Cleveland.

Devido a uma experiência traumática no passado, Hank tem medo de viver na natureza e prefere viver em cativeiro. Sendo assim, ele faz um acordo com Dory para ajudá-la a encontrar seus pais em troca de sua etiqueta.

Depois de observar várias pistas e recordando fragmentos de sua memória, Dory deduz que nasceu na seção "Oceano aberto", do Instituto, e que deve ser onde seus pais estão. Ao longo do caminho, pede ajuda para sua amiga de infância Destiny, uma tubarão míope, e Bailey, uma baleia beluga que acredita ter perdido o uso da capacidade de eco localização. Depois de chegar até sua antiga casa, no "Oceano aberto", Dory descobre que todos os peixes espigas azuis estão sendo 
transferidos para Cleveland, o que significa que seus pais devem ter ido parar de volta na quarentena.

Enquanto isso, Marlyn e Nemo tentam resgatar Dory, contando com a ajuda de um par de Leões marinhos chamados Fluke e Leme. Os leões os apresentam para sua amiga Becky, uma ave grande e amigável.

Através de um balde, Becky consegue colocá-los dentro do instituto. Após algum tempo Marlyn e Nemo conseguem encontrar Dory.

Reunidos, o trio vai para quarentena, onde conseguem encontrar o tanque em que as espigas azuis estão sendo mantidas. No entanto, as espigas azuis de lá explicam que quando a jovem Dory foi sugada pelos canos do instituto e acabou caindo no mar, seus pais foram atrás dela na quarentena procurá-la, mas nunca mais retornaram para o "Oceano aberto", indicando, que provavelmente, morreram na tentativa. Enquanto Dory está em choque com a notícia, Hank tenta retirar Dory, Marlyn e Nemo do caminhão com destino à Cleveland. Porém só consegue retirar Dory, e acidentalmente joga-a no mar. Nesse momento, Dory esquece o porque encontra-se no mar. Vagueando inconsolavelmente pelo mar, ela se depara com vários rastros de conchas. Nessa situação, acaba se lembrando que seus pais lhe ensinaram, que se algum dia, ela se perdesse, era só ficar calma e seguir os rastros de conchas de volta para casa. Dory segue a trilha e acaba encontrando com seus pais Charlie e Jenny.

Os pais explicam para Dory que quando não a acharam na quarentena, deduziram que ela tinha escapado para o oceano. Sendo assim, eles deram um jeito de escapar do instituto e estabeleceram várias trilhas de conchas nas águas do oceano que existe ali por perto. 
Feliz por estar de volta com a sua família, Dory de repente se lembra que precisa resgatar Marlyn e Nemo.

Destiny e Bailey escapam de seus aquários para ajudar Dory a resgatar Nemo e Marlyn. As lontrinhas da região conseguem temporariamente interceptar o trânsito, em uma ponte, e parar o caminhão que transportava Nemo e Marlyn. Nesse momento, Destiny aproveita para lançar Dory aos céus, com sua cauda. As lontras conseguem capturar Dory e colocá-la no caminhão. Assim que Hank começa a dirigir o caminhão, ele o direciona rumo a um penhasco. $\mathrm{O}$ caminhão é jogado no mar e dessa maneira acaba libertando todos os animais que seriam transportados para Cleveland na água. Com muito custo, Dory convence Hank a viver na natureza, e assim, reunidos, Dory, seus pais, Hank, Destiny, e Bailey voltam com Marlyn e Nemo para viver uma nova vida na Grande Barreira de Corais.

\section{METODOLOGIA}

A metodologia desse estudo propõe a utilização dos personagens presentes em uma animação comercial, intitulada "Procurando Dory" (2016), no ensino de Ciências e Biologia. O filme citado anteriormente foi escolhido, no presente estudo, já que apresenta relevantes aspectos relacionados com a vida marinha dos animais e que podem facilmente ser discutidos no ensino. A proposta, é que os tópicos aqui apresentados possam ser debatidos durante ou depois da exibição do filme, em sala de aula, para alunos do ensino fundamental e/ou ensino médio. Como metodologia de ensino selecionaram-se oito principais personagens do filme: Dory, Marlyn, Nemo, Tio Raia, Crush, Hank, Destiny e Bailey. Em seguida, características dos personagens como: localização geográfica, alimentação, reprodução, morfologia, fisiologia, habitat e relações ecológicas, foram listadas e propostas para discussão. A ideia é que o professor se aproprie do filme como uma 
maneira de facilitar o inicio da apresentação de determinados conteúdos ou até mesmo uma revisão sobre determinados assuntos. Sugerimos que o professor não só utilize os tópicos aqui apontados para debate, mas que amplie o diálogo com outros aspectos de seu interesse. É necessário que os docentes testem a eficácia das temáticas aqui ofertadas, já que o presente estudo não o fez, e que se acharem necessário, que efetuem modificações nas mesmas visando destacar ainda mais os aspectos biológicos dos animais representados nessa animação.

\section{RESULTADOS \& DISCUSSÃO}

Para enriquecer o aprendizado de seus alunos, os professores de Ciências e de Biologia, durante ou após exibirem o filme "Procurando Dory", podem discutir alguns aspectos existentes nos personagens, a saber:

\subsection{Morfologia}

Pelo personagem existente na figura 1, é possivel discutir com os alunos o formato pontiagudo, que lembra um bisturi de cirurgião, que a cauda do peixe "Dory" Paracanthurus hepatus (fig.1) apresenta, esclarecendo aos mesmos que é por esse motivo que o animal possui o nome popular de "Cirurgião Hepatus" (DIAS, 2007).

Para trabalhar os aspectos morfológicos desse peixe, podem ainda, explicar aos discentes que indivíduos dessa espécie medem cerca de 20 a $30 \mathrm{~cm}$ e possuem corpos achatados que recordam uma palheta. Quando na época juvenil, exibem uma cor amarelada bem vibrante e aos poucos, com o passar dos anos, essa cor vai mudando para um amarelo misturado com azul. 


\subsection{Alimentação}

Da mesma maneira, para os aspectos alimentares da espécie (fig.1), proveitoso seria relatar que a sua alimentação consiste basicamente de algas marinhas e camarões. Sendo assim, a espécie é de extrema valia para os recifes de corais, já que impedem o crescimento exagerado das algas, fato esse que poderia levar ao sufocamento desses cnidários (CONRADT, 2016).

\subsection{Distribuição geográfica}

A localização geográfica da espécie (fig.1), no mundo, não deve ser esquecida. Para isso, os professores podem evidenciar, em um mapa do globo terrestre, a região sudoeste do Pacífico, Oceano Índico, as costas da Austrália e África Oriental aos alunos, e ainda, destacar que a Flórida, Caribe, e Bahamas são os locais em que esses peixes são encontrados em maior quantidade (DIAS, 2007).

\subsection{Aspectos antropológicos}

É importante discutir e alertar os alunos, que apesar desse peixe (fig.1) ser geralmente caçado por pessoas para vendê-los em pet shops, a carne em si não é boa, podendo causar envenenamento, já que é esse um dos mecanismos de defesa que a espécie manifesta contra seus predadores (DIAS, 2007; CONRADT, 2016).

Outro curioso fato é que apesar da sua adorável e meiga aparência no filme, a "Dory" da vida real é bastante agressiva e pode cortar aqueles que tentam pegá-la (CONRADT, 2016). Isso acontece já que essa espécie apresenta espinhas caudais bastante afiadas e que podem ser projetadas para fora do corpo.

E por fim, cabe aos professores destacar ainda que com o lançamento do filme "Procurando Dory" as vendas desse peixe (fig.1) podem aumentar no mercado internacional. Exemplo similar ocorreu quando a Disney e Pixar lançaram "Procurando 
Nemo", há 13 anos atrás, período em que as vendas de peixespalhaço (fig.2) aumentaram consideravelmente. Entretanto, a criação em viveiro reduziu o impacto que poderia ocorrer se esses indivíduos fossem retirados do seu habitat natural, os recifes de coral (ARSÉNIO, 2016).

\section{Figura 1 - Personagem Dory (Paracanthurus hepatus) do filme Procurando Dory (2016)}

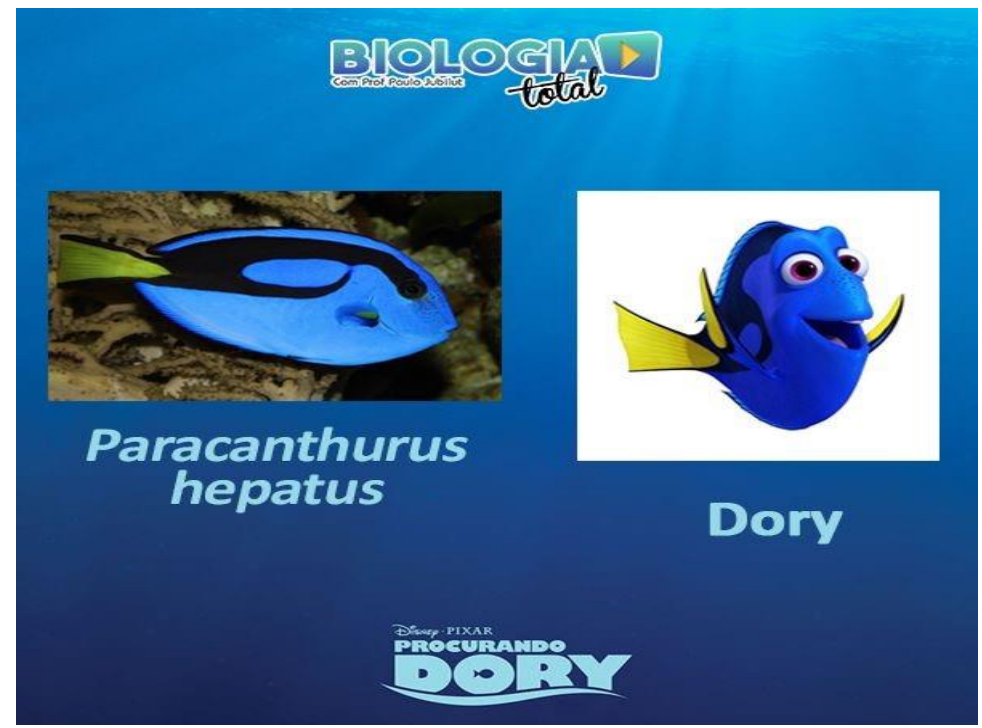

Créditos das imagens: Prof. Paulo Jubilut. http://site.biologiatotal.com.br/.

\subsection{Relações ecológicas}

Para os personagens representados pela figura 2, (Marlyn e Nemo), Amphiprion sp, pode-se ensinar que existem mais de 30 espécies de peixe palhaço, sendo encontradas por toda a região Oeste dos Oceanos Índico e Pacífico, concentrando-se, em maior quantidade, na região dos arquipélagos das Filipinas. Um relevante aspecto, também a ser debatido com os alunos, é o fato de que o peixe palhaço na natureza não consegue sobreviver sem a presença de uma anêmona, pois são estas que the fornecem abrigo, proteção, delimitam seus territórios, afastam possiveis predadores e ainda servem como local de desova (CANTINI, 2008). 
Sugere-se, para trabalhar os conceitos de ecologia das relações simbióticas, salientar aos estudantes que, para que as anêmonas possam se alimentar, essas necessitam produzir uma substância urticante, que ajuda a capturar pequenas presas, como pequenos peixes. Só que os peixes-palhaço (fig. 2) possuem o corpo revestido por um muco que os protege dos espigões venenosos existentes nos tentáculos das anêmonas. Sendo assim, a anêmona e o peixe-palhaço conseguem viver em uma relação simbiótica em que ambos saem ganhando. O peixe-palhaço ganha a proteção de viver entre os tentáculos das anêmonas, e as anêmonas ganham os restos de comida que os peixes-palhaço acabam deixando cair (CANTINI, 2008).

\subsection{Reprodução}

Para trabalhar o conteúdo de reprodução, um notável aspecto que pode ser discutido é a questão do hermafroditismo. Os peixes palhaços (fig.2) são hermafroditas sequenciais, ou seja, alternadamente conseguem mudar de sexo, mas nunca conseguem ser dos dois sexos ao mesmo tempo. Portanto, se ocorresse na vida real o que aconteceu no filme "Procurando Nemo" (2003), quando a matriarca da família foi morta, o percurso natural que o pai (Marlyn) deveria seguir era transformar-se em uma fêmea, e a seguir, copular com o seu filhote (Nemo) (PRONIN, 2014). 


\section{Figura 2 - Personagens Marlyn e Nemo (Amphiprion sp.) do filme Procurando Dory (2016)}

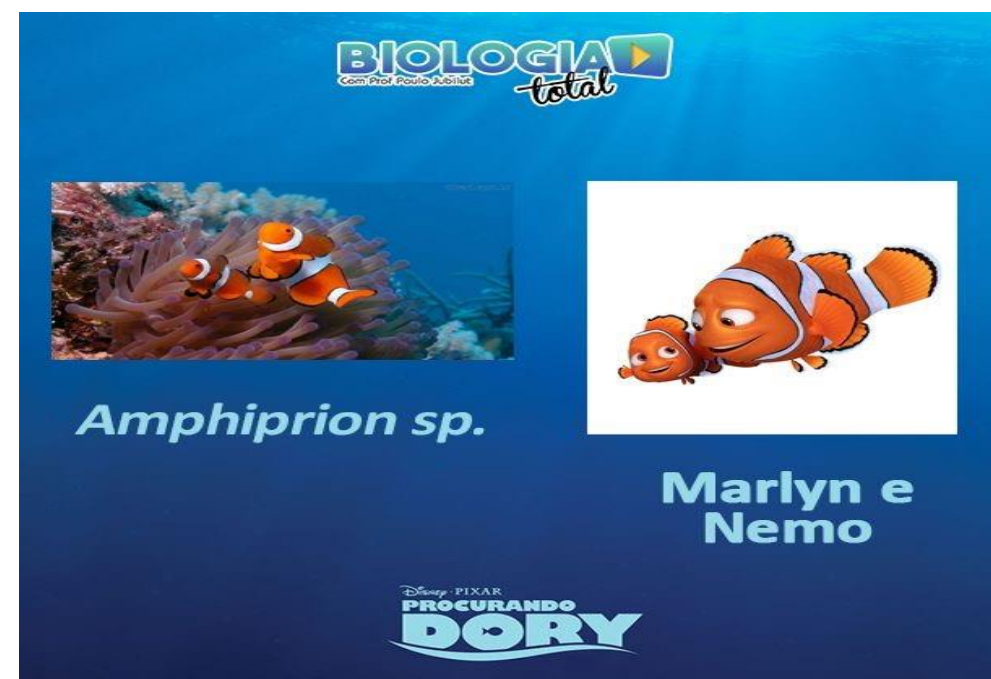

Créditos das imagens: Prof. Paulo Jubilut. http://site.biologiatotal.com.br/.

\subsection{Alimentação}

Para a figura 3, que representa o personagem Tio Raia (Aetobatus narinari), os professores podem discutir os aspectos alimentares dessa espécie com os alunos, evidenciando que a alimentação consiste em crustáceos, plânctons, moluscos, caramujos, camarões, polvos e pequenos peixes. Da mesma maneira, pode-se evidenciar que a estratégia utilizada pela raia na captura do alimento fundamenta-se em ficar semienterrada na areia, do fundo do mar, esperando o animal se aproximar. Quando a presa se aproxima, ela dá um rápido e certeiro bote com a cauda, que possui uma forte peçonha. Cobrem a vitima com suas nadadeiras peitorais e, em seguida, abocanham a presa (BIONDI, 2012). Importante, nesse momento, seria salientar a morte do naturalista Steve Irwin, apresentador do programa "Caçador de crocodilos" no canal Animal Planet, que faleceu devido ao ataque de uma arraia (FOLHA ONLINE, 2006). Dessa maneira, é possivel conscientizar os alunos sobre os perigos que esse animal (fig. 3) representa na natureza quando incomodado. 


\section{Figura 3 - Personagem Tio Raia (Aetobatus narinari) do filme Procurando Dory (2016)}

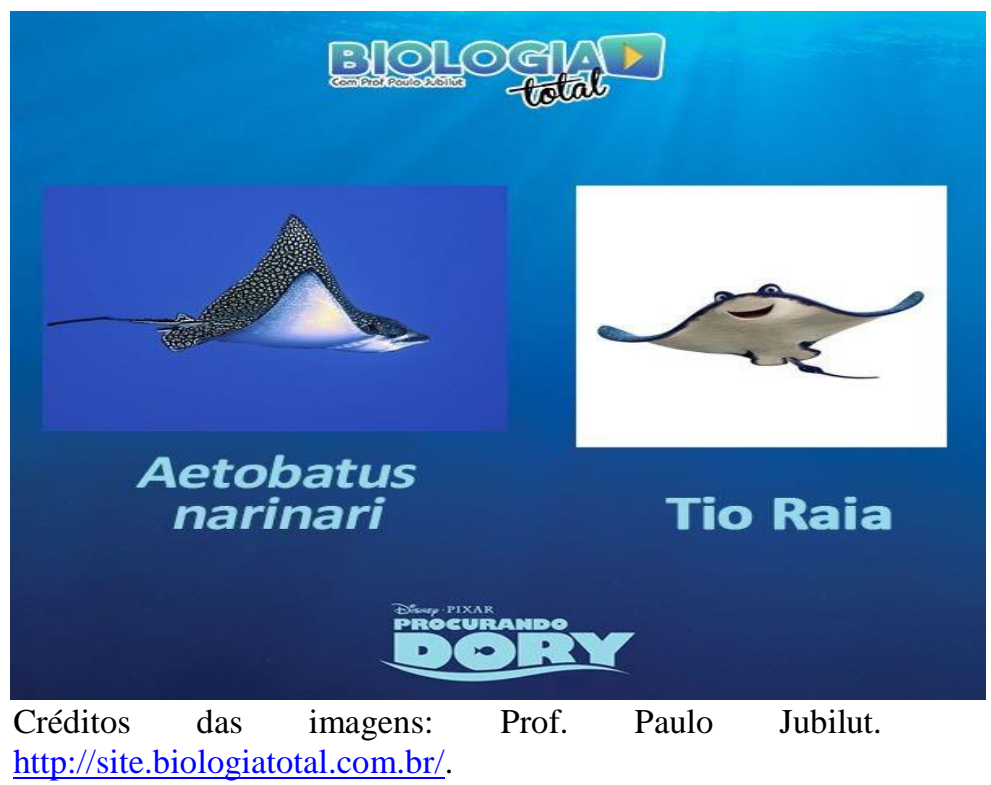

\subsection{Reprodução}

$\mathrm{Na}$ figura 4 está representada uma tartaruga marinha denominada Crush (Chelonia mydas). Os professores de Ciências e Biologia podem abordar com seus alunos que o Brasil é um país que abriga cinco das sete espécies de tartarugas marinhas existentes no mundo (FIOCRUZ, 2010). Do mesmo modo, salientar a importância que o litoral nordestino brasileiro apresenta como área alimentar para a espécie representada pelo personagem Crush, nos períodos que esses indivíduos estão realizando suas desovas. Outro aspecto fundamental de se trabalhar com os alunos é o fato de que a temperatura do ninho que irá determinar o sexo dos filhotes. Portanto, baixas temperaturas durante a incubação produzem machos e altas temperaturas produzem fêmeas (POUGH et al., 2008). Nesse momento pode-se perguntar aos alunos como o aquecimento global afeta esse processo. 


\section{Figura 4 - Personagem Crush (Chelonia mydas) do filme procurando Dory}

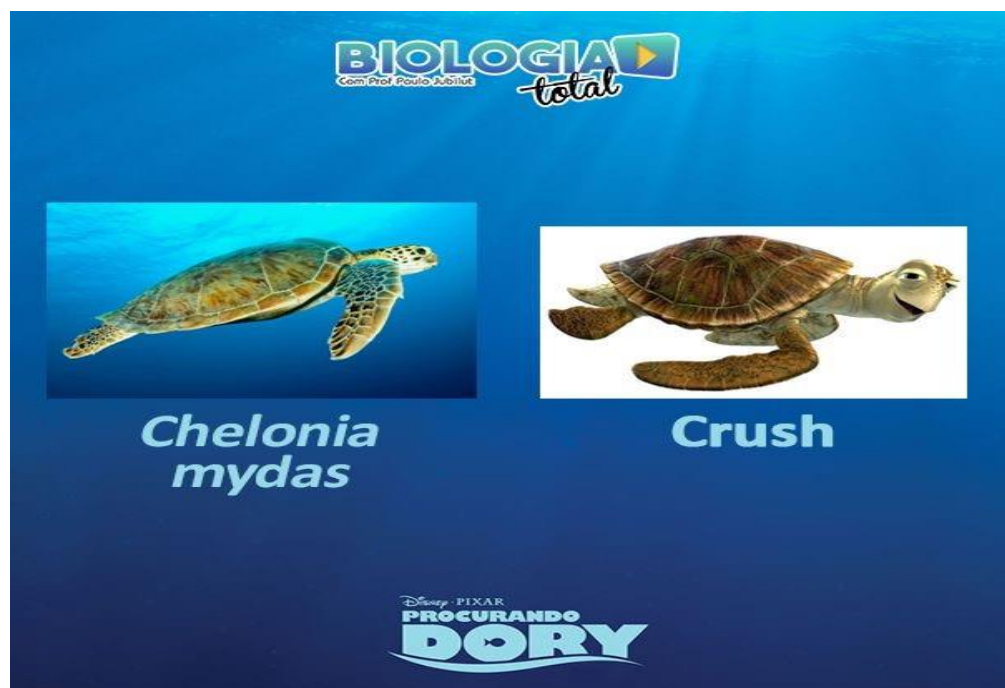

Créditos das imagens: Prof. Paulo Jubilut. http://site.biologiatotal.com.br/.

\subsection{Reprodução}

$\mathrm{Na}$ figura 5, que possui o personagem Hank (Polvo), interessante discutir com os alunos que na época da reprodução, a fêmea do polvo libera hormônios na água para atrair os machos. Após o acasalamento, põe os ovos, cerca de $150 \mathrm{mil}$, no interior de buracos existentes em rochas no fundo do mar, e fica cuidando para que não sejam predados. Durante o tempo em que a fêmea fica vigiando seus ovos, a mesma não se alimenta e, por esse motivo, morre logo depois que os filhotes saem dos ovos (LOUREDO, 2016).

\subsection{Estratégias antipredação}

Além disso, outro aspecto que possui relevância é que esse animal (fig.5) possui várias formas de se defender de seus predadores, e uma delas é a liberação de uma tinta escura para despistar o inimigo enquanto foge, como é possivel ver na cena em que Hank e Dory fogem das mãos dos visitantes no tanque.

Em outras vezes, quando o inimigo consegue prender um dos tentáculos desse animal, o mesmo deixa esse tentáculo com o inimigo e foge em disparada. Dias depois, outro tentáculo nasce no lugar do que foi 
arrancado (LOUREDO, 2016). Outra forma que o polvo utiliza para se defender é a camuflagem. Em questão de segundos esse animal é capaz de mudar completamente de cor, ficando com as mesmas cores da areia ou de uma pedra, enganando seus predadores e também suas presas. Tudo isso graças a pigmentos existentes em suas células epidérmicas. Podemos perceber essa característica em várias cenas do filme.

\section{Figura 5 - Personagem Hank (Polvo) do filme Procurando Dory.}

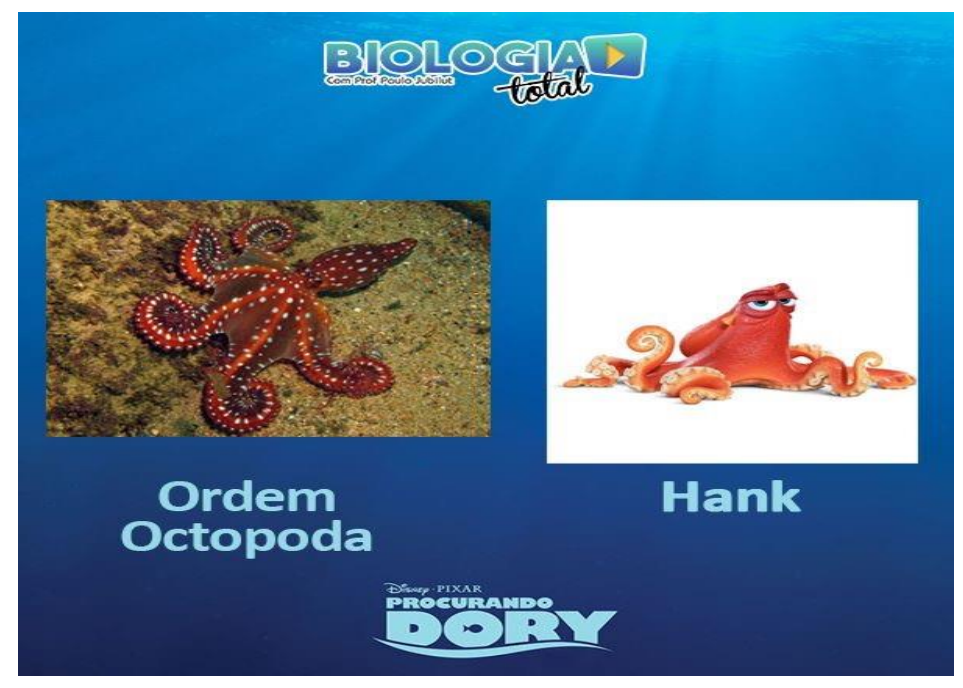

Créditos das imagens: Prof. Paulo Jubilut. http://site.biologiatotal.com.br/.

\subsection{Características biológicas}

A figura 6 exibe a personagem Destiny (Rhincodon typus), uma tubarão baleia. Pode-se explorar com os alunos o fato de que o tubarão baleia é o maior peixe do mundo podendo atingir 20 metros de comprimento e pesar mais de 12 toneladas. Porém, apesar de ser um animal gigantesco, o tubarão-baleia não é um grande predador dos oceanos. Alimenta-se de pequenos organismos, tais como pequenos crustáceos que formam o chamado plâncton, podendo também comer alguns peixes e moluscos. Para alimentar-se, utiliza uma estratégia bastante peculiar para um animal tão grande: a sucção e a filtração (SANTOS, 2016). 


\subsection{Habitat}

Os tubarões-baleia são encontrados frequentemente nas mesmas áreas todos os anos, provavelmente em razão da fartura de alimentos em certas regiões. Aqui no Brasil, é encontrado praticamente em toda a costa, porém são mais frequentemente avistados no arquipélago de São Pedro e São Paulo, em Pernambuco (SANTOS, 2016).

Atualmente os tubarões-baleia estão classificados como vulneráveis na Lista Vermelha da União Internacional para Conservação da Natureza (IUCN). Apesar de protegidos por lei em alguns lugares do mundo, a caça é permitida em certas regiões, como em Taiwan (SANTOS, 2016).

\section{Figura 6 - Personagem Destiny (Rhincodon typus) do filme Procurando Dory (2016)}

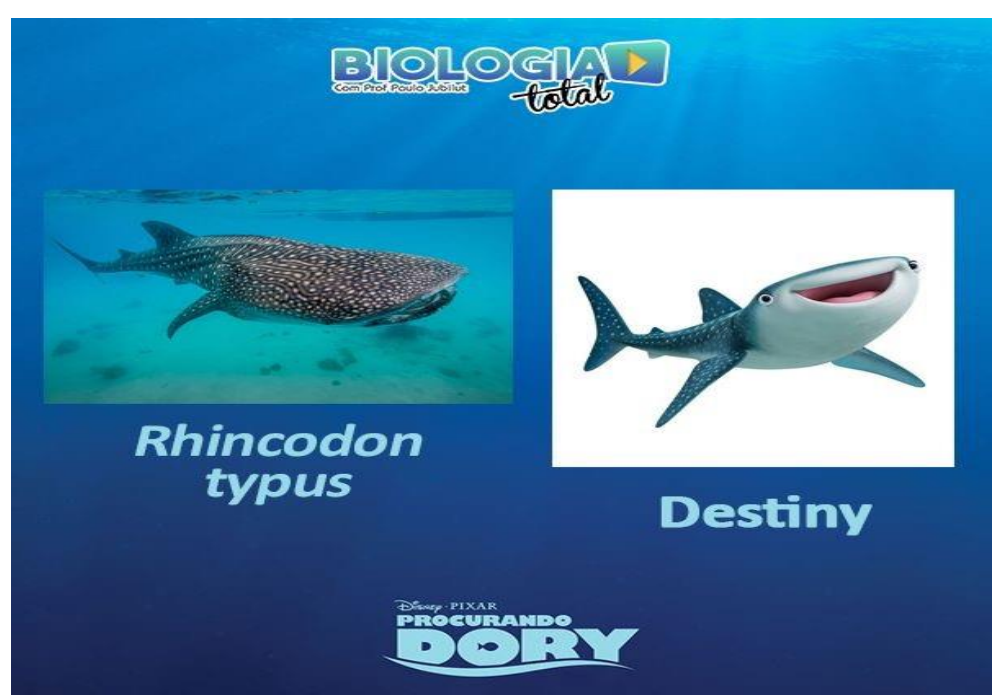

Créditos das imagens: Prof. Paulo Jubilut. http://site.biologiatotal.com.br/.

Na figura 7, está apresentada a baleia chamada Bailey (Delphinapterus leucas). O professor pode abordar com os alunos sobre essa personagem o fato de que essas baleias utilizam a eco localização, ou seja, detectam objetos através da emissão de ondas sonoras. Logo, através da eco localização, esses animais conseguem encontrar buracos de respiração no gelo, e caçar em águas escuras ou turvas. 


\section{Figura 7 - Personagem Bailey (Delphinapterus leucas) do filme Procurando Dory (2016)}

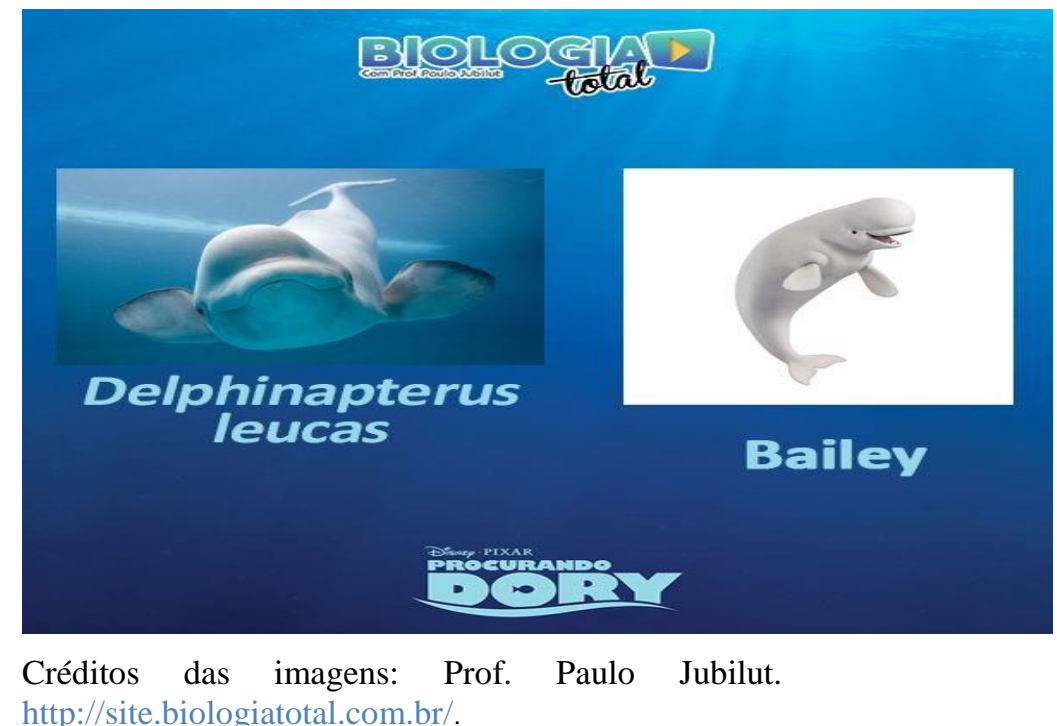

\section{CONSIDERAÇÕES FINAIS}

Construimos nesse trabalho uma proposta para trabalhar na Educação Básica aspectos biológicos utilizando a animação Procurando Dory (2016). Espera-se que os professores de Ciências e Biologia tenham acesso a essa atividade e que possam, de acordo com os seus anseios, trabalhar os diferentes conteúdos que se fazem presentes nos personagens do filme.

Com o material apresentado nesse estudo os docentes podem discutir variados conteúdos com seus alunos, como por exemplo: Morfologia, Alimentação, Distribuição geográfica, Aspectos antropológicos, Relações ecológicas, Reprodução, Características biológicas e Habitat dos principais personagens existentes na animação.

Salientamos que o presente estudo não pretendeu abordar todos os aspectos biológicos de todos os personagens existentes no filme. Portanto, abre-se também, perspectivas para que outros personagens possam ser estudados e associados ao ensino de Ciências e Biologia. Pretende-se, ainda, despertar a criatividade dos professores, de forma que os mesmos possam desenvolver outras atividades como essa, em suas práticas educativas. 
Por fim, as discussões aqui apresentadas poderão ser realizadas durante ou depois que o professor exibir o filme para seus alunos. A ideia é que os docentes se apropriem do filme para iniciar ou então fazer uma revisão sobre determinados conteúdos biológicos.

O presente estudo mostrou como o filme Procurando Dory (2016) pode ser aproximado do Ensino de Ciências e Biologia, e como o cinema pode ser entendido como uma ferramenta capaz de fomentar reflexões e discussões. Infelizmente, na atualidade, a educação escolar tem acontecido, na maioria das vezes, por meio da pura transmissão de informações prontas apresentadas nos livros didáticos, não estimulando o raciocínio e a busca por soluções por parte dos alunos (SOBRINHO, 2009). Considerando esse contexto, é necessário repensar e reavaliar a maneira como o ensino é realizado, bem como buscar novas metodologias que venham a aprimorar as formas tradicionais de ensino. Sendo assim, o uso do cinema como estratégia pedagógica e educacional pode ser de grande valia para o processo de ensino e aprendizagem, não somente para a apresentação dos conteúdos exigidos na escola, mas também para a formação do caráter integral do individuo (BARROS; GIRASOLE; ZANELLA, 2013).

Ensinar Ciências ou Biologia é um grande desafio para os educadores. Isso ocorre em virtude do caos em que o processo educacional em nosso país está mergulhado, tendo uma crescente desvalorização do professor e a mercadorização do ensino, banalizando, dessa forma, o processo de ensinoaprendizagem. Nessa perspectiva, através desse trabalho, procuramos direcionar nossa pesquisa de modo a adotá-la como uma estratégia didática, confiando ao professor o papel principal de mediador, para que este proporcione aos estudantes a possibilidade de reflexão sobre o que está contido nos livros didáticos e nas demais fontes de informação, relacionando as mesmas com a leitura das imagens reveladas pelo cinema. Desta forma, ao associarmos o aprendizado científico com o cinematográfico, é possível que os alunos criem uma visão crítica e, ainda, contextualizada da sociedade que fazem parte (AUSUBEL, 1982; FREIRE, 1996). Assim sendo, o presente estudo pode contribuir para a prática de utilização do cinema dentro da sala 
de aula como estratégia pedagógica e não somente como uma mera forma de entretenimento. Acreditamos que o presente trabalho resgata a sua função e verdadeiro valor como elemento auxiliar na formação do indivíduo, a partir do momento que passa a ser uma importante alternativa para estreitar o diálogo entre alunos, professores e o conhecimento científico.

\section{REFERÊNCIAS BIBLIOGRÁFICAS}

A EVOLUÇÃO DA ANIMAÇÃO. Revista Época Online. 3. Dez. 2004. Disponivel em: <http://revistaepoca.globo.com/Revista/Epoca/0,,EDG678205856,00.html>. Acesso em: 25 jul. 2016.

ADAMSON, A.; JENSON, V. Shrek (2001). Duração: 1 h 30 min. Cor: Colorido. Comprimento do filme: $2.531 \mathrm{~m}$. Formato negativo: Digital. Lançamento: 22 de Abril de 2001. País: USA.

ALLERS, R.; MINKOFF, R. O Rei Leão (1994). Duração: 1 h 29 min. Cor: Colorido. Formato negativo: $35 \mathrm{~mm}$. Lançamento: 12 de Junho de 1994. País: USA.

ALGAR, J. [...] Fantasia (1940). Duração: 2 h 5 min. Mixagem de som:

Stereo. Cor: Colorido. Comprimento do filme: 7.360 m. Formato negativo: 35 mm. Lançamento: 13 de Novembro de 1940. País: USA.

ARAÚJO, I. Cinema - o mundo em movimento. São Paulo: Scipione, 1995. $103 \mathrm{p}$.

ARMSTRONG, S. [...] Dumbo (1941). Duração: 1 h 4 min. Cor: Colorido. Comprimento do filme: $1.747 \mathrm{~m}$. Formato negativo: $35 \mathrm{~mm}$. Lançamento: 23 de Outubro de 1941. País: USA.

ARSÉNIO, C. Veja o filme, não compre o peixe. Publicado em: 23/06/2016. Disponivel em: < http://www.tsf.pt/cultura/arte/interior/veja-o-filme-naocompre-o-peixe-5242591.html>. Acesso em: 27 jul. 2016.

AUSUBEL, D. P. A aprendizagem significativa: a teoria de David Ausubel. São Paulo: Moraes, 1982. $111 \mathrm{p}$.

BARROS, M. D. M.; COSTA, E. C. P. O filme 'O milagre de Anne Sullivan' auxiliando o trabalho do professor na escola: contribuições para uma educação inclusiva na formação de docentes. Sinapse Múltipla, Betim (MG), v. 3, p. 77-85, 2014.

BARROS, M. D. M.; GIRASOLE, M.; ZANELLA, P. G. O uso do cinema como estratégia pedagógica para o ensino de ciências e de biologia: o que pensam alguns professores da região metropolitana de Belo Horizonte. Revista Práxis (Online), Volta Redonda (RJ), v. 5, p. 97-115, 2013.

BIONDI, R. Raia pintada. Mundo Marinho, publicado em 25 de março de 2012. Disponivel em: <

http://mundomarinhobr.blogspot.com.br/2012/03/raia-pintada.html>. Acesso em: $01 \mathrm{dez} .2016$.

BIRD, B. Os Incriveis (2004). Duração: 1 h 55 min. Cor: Colorido. Formato negativo: Digital. Lançamento: 27 de Outubro de 2004. País: UK (Londres). 
BLACKTON, J. S. Humorous Phases of Funny Faces (1906). Duração: 3 min. Som: Silencioso. Cor: Preto e Branco. Comprimento do filme: $70 \mathrm{~m}$. Formato negativo: $35 \mathrm{~mm}$. Lançamento: 6 de Abril de 1906. País: USA.

CAMPANINI, B. D; BORIM, D. C. D. E.; ROCHA, M. B.; BARROS, M. D. M. Divulgação científica na escola: $\mathrm{O}$ uso do filme Frankenweenie como recurso didático no ensino de Biologia. Revista de Ensino de Biologia da Associação Brasileira de Ensino de Biologia (SBEnBio), Niterói (RJ), n. 9. p. 381-391. 2016.

CAMPOS, P. M. C.; SOARES, R. C. C.; BATISTA, S. M.; BARROS, M. D. M. Guia do educador para o filme Filadélfia. Tecnologia \& Cultura (CEFET/RJ), v. 26, p. 62-73, 2015.

CANEMAKER, J. Felix: The Twisted Tale of the World's Most Famous Cat. Pantheon Books, Nova Iorque. $1^{\circ}$ ed. 1991. 117p.

CANTINI, M. Peixe palhaço ou Nemo. Publicado em: 27/06/2008. Disponivel em: <http: / / especiesmarinhas.blogspot.com.br/2008/07/peixe-palhao-ounemo.html>. Acesso em: 27 jul. 2016.

CLEMENTS, R., MUSKER, J. A Pequena Sereia (1989). Duração: 1 h 23 min. Cor: Colorido. Formato negativo: $35 \mathrm{~mm}$. Processo cinematográfico: Esférico. Formato de impressão do filme: $35 \mathrm{~mm}$. Lançamento: 15 de Novembro de 1989. País: USA.

COELHO, R. M. F.; VIANA, M. C. V. A utilização de filmes em sala de aula: um breve estudo no instituto de ciências exatas e biológicas da UFOP.

Revista da Educação Matemática da UFOP, Ouro Preto (MG), v. 1, p 89-97. 2011.

COELHO, C.; MAGALHÃES, M.; QUEIROZ, A.; ZAGURY, L. Animation now! Madrid: Taschen, 2004. Audiobook.

COHL, É. Fantasmagorie (1908). Duração: 2 min. Cor: Preto e branco. Comprimento do filme: $36 \mathrm{~m}$. Formato negativo: $35 \mathrm{~mm}$. Processo cinematográfico: Esférico. Formato de impressão do filme: $35 \mathrm{~mm}$. Lançamento: 17 de Agosto de 1908. País: França (Paris).

CONRADT, S. Understanding 'Dory': 5 Facts about the Pacific Blue Tang. Publicado em 17/06/2016. Disponivel em:

$<$ http:/ / mentalfloss.com/article/81758/understanding-dory-5-facts-aboutpacific-blue-tang>. Acesso em: 27 jul. 2016.

COSTA, E. C. P.; BARROS, M. D. M. Luz, câmera, ação: o uso de filmes como estratégia para o ensino de Ciências e Biologia. Revista Práxis (Online), Volta Redonda (RJ), v.6, p. 81-93, 2014.

COTTRELL, W. [...] Branca de Neve e os Sete Anões (1937). Duração: 1 h 23 min. Comprimento do filme: 510 m. Formato negativo: 35 mm. 21 de Dezembro de 1937. País: USA.

DIAS, G. Peixe Blue Tang. Publicado em 11/12/2007. Disponivel em: <http://www.bichosbrasil.com.br/peixe-blue-tang/>. Acesso em: 27 jul. 2016.

DOCTER, P.; PETERSON, B. Up: Altas Aventuras (2009). Duração: 1 h 36 min. Comprimento do filme: 2.655 m. Formato negativo: Digital. 13 de Maio de 2009. País: França. 
DOURADO - JUNIOR, L. A. Evolução paralela da ciência e da arte e sua convergência na produção de material didático para o ensino de biociências. Rio de Janeiro: UFRJ, 120p. Tese (Doutorado em Química Biológica) Programa de Pós-Graduação em Química Biológica, Universidade Federal do Rio de Janeiro, Rio de Janeiro, 2007.

D`ROSSI, N. Cassiopéia. Diretor: Clóvis Vieira. Produção: NDR Filmes. Duração: 1h20. Publicado em: 8 de novembro de 2002. Disponivel em: <http:/ / www.mci.org.br/historia/cassiopeia/cassiopeia.html>. Acesso em: 26 jul. 2016.

DUARTE, R. Cinema \& educação. Belo Horizonte: Autêntica, 2002 - 2. Ed. $126 \mathrm{p}$.

ELIOT, M. Walt Disney: O principe sombrio de Hollywood. São Paulo: Marco Zero, 1993. 382p.

FACEBOOK. Biologia com o Prof. Jubilut. Publicado em 15 de julho de 2016. Disponivel em:

<https://www.facebook.com/biologiajubilut/photos / ?tab=album\&album_id =342439539171747> . Acesso em: 10 ago. 2016 .

FIOCRUZ. Algumas curiosidades sobre as tartarugas marinhas e o Projeto Tamar. Publicado em 19 de outubro de 2010. Disponivel em: < http:/ /www.olimpiada.fiocruz.br/algumas-curiosidades-sobre-tartarugasmarinhas-e-o-projeto-tamar>. Acesso em: $01 \mathrm{dez} .2016$.

FOLHA ONLINE. Arraia mata Steve Irwin, 44, o "caçador de crocodilos" do Animal Planet. Publicado em 4 de setembro de 2006. Disponivel em: < http:/ / www1.folha.uol.com.br/folha/ciencia/ult306u15129.shtml>. Acesso em: 01dez. 2016.

FOSSATTI, C. L. Cinema de Animação: Uma trajetória marcada por inovações. Trabalho apresentado no $7^{\circ}$ Encontro Nacional de História da Midia - midia alternativa e alternativas midiáticas. 19 a 21 de Agosto de 2009, Fortaleza, Ceará.

FREIRE, P. Pedagogia da Autonomia: saberes necessários à prática pedagógica. São Paulo: Paz e Terra, 1996. 52p. (Coleção Leitura).

GERONIMI, C. [...] Cinderela (1950). Duração: 1 h 14 min. Cor: Colorido. Comprimento do filme: $453 \mathrm{~m}$. Formato negativo: $35 \mathrm{~mm}$. Lançamento: 15 de Fevereiro de 1950. País: USA.

GERONIMI, C. [...] Alice no país das Maravilhas (1951). Duração: 1 h 15 min. Cor: Colorido. Comprimento do filme: 2.122,93 m. Formato negativo: $35 \mathrm{~mm}$. Lancamento: 26 de Julho de 1951. Pais: USA.

. As aventuras de Peter Pan (1953). Duração: 1 h 17 min. Cor:

Colorido. Comprimento do filme: $470 \mathrm{~m}$. Formato negativo: $35 \mathrm{~mm}$.

Lancamento: 5 de Fevereiro de 1953. País: USA.

. A Guerra dos Dálmatas (1961). Duração: 1 h 19 min. Cor: Colorido.

Comprimento do filme: $2.175 \mathrm{~m}$. Formato negativo: $35 \mathrm{~mm}$. Lancamento: 25 de Janeiro de 1961. País: USA.

GUILLÉN, J. M. El cine de animación: En más de 100 longametrajes. Madri:

Alianza, 1997. 304p. ISBN: 9788420694856

JUBILUT, P. Biologia total. Disponivel em: <

http://site.biologiatotal.com.br/>. Acesso em: 05 dez. 2016. 
LASSETER, J. Toy Story (1995). Duração: 1 h 21 min. Cor: Colorido. Comprimento do filme: $2.211 \mathrm{~m}$. Formato negativo: Digital. Lançamento: 19 de Novembro de 1995. País: USA.

LORD, P.; PARK, N. A Fuga das Galinhas (2000). Duração: 1 h 24 min. Cor: Colorido. Comprimento do filme: $2.399 \mathrm{~m}$. Formato negativo: $35 \mathrm{~mm}$. Lançamento: 21 de Junho de 2000. País: USA.

LOUREDO, P. Polvos. Escola Kids. Disponivel em: <http:/ / escolakids.uol.com.br/polvos.htm>. Acesso em: 01 dez. 2016. LUCENA JÚNIOR, A. Arte da animação: Técnica e estética através da história. São Paulo: Senac, 2001. 456p. ISBN: $8573592192,9788573592191$. MATTA, R. R.; BARROS, M. D.M. O ensino de ciências e a educação científica: potencialidades do filme 'Tá chovendo hambúrguer 2'. In: II CONAPESC - Congresso Nacional de Pesquisa e Ensino em Ciências, 2017, Campina Grande. Anais II CONAPESC. Campina Grande: Editora Realize, 2017. v. 1.

McCAY, W. Gertie, the Dinosaur (1914). Duração: 12 min. Cor: Preto e Branco. Comprimento do filme: $300 \mathrm{~m}$. Formato negativo: $34 \mathrm{~mm}$. Processo cinematográfico: Esférico. Lançamento: 15 de Setembro de 1914. País: USA. MORRISON, M. Becoming a computer animator. Indianápolis: Howard W. Sams, 1994. 200p. ISBN: 0672304635

NASCIMENTO, J. M. L.; MEIRELLES, R. M. S.; SILVA, M. M.; NASCIMENTO, R. L.; BARROS, M. D. M. Guia do educador para o filme X-Men primeira classe. Genética na Escola, Ribeirão Preto (SP), v. 11, p. 28-35, 2016. NOWELL-SMITH, G. The Oxford History of World Cinema. Oxford University Press, UK. 1996. 342p. ISBN: 9780198742425

PENNER, E. [...] A Bela Adormecida (1959). Duração: 1 h 15 min. Cor: Colorido. Comprimento do filme: $2060 \mathrm{~m}$. Formato negativo: $35 \mathrm{~mm}$. Lançamento: 29 de Janeiro de 1959. País: USA.

PEREIRA, P. A. R.; BARROS, M. D. M. Guia do educador para o filme Rango. Revista Pedagogia em Foco, São Carlos (SP), v. 12, p. 205-222, 2017. PIN, J. R. O.; ARAUJO, C. A. S.; BARROS, M. D. M.; ROCHA, M. B. Levando o cinema para a sala de aula: a construção de um guia do educador para o filme 'Lucas, um intruso no formigueiro'. Revista de Ensino de Biologia da Associação Brasileira de Ensino de Biologia (SBEnBIO), Niterói (RJ), v. 9, p. 357-368, 2016.

PINTO, L. F. O historiador e sua relação com o cinema. Revista Eletrônica $O$ Olho da História, n.6, p.1. 2004.

POUGH, H. F.; JANIS, C. M.; HEISER, J. B. A vida dos vertebrados. 4. ed. São Paulo: Atheneu, 2008. 750p.

PRONIN, T. Clique Ciência: sabia que o pai do Nemo deveria ter virado fêmea? Publicado em: 15/07/2014. Disponivel em: $<$ http:/ / noticias.uol.com.br/ciencia/ultimasnoticias / redacao/2014/07/15/clique-ciencia-sabia-que-o-pai-do-nemodeveria-ter-virado-femea.htm>. Acesso em: 27 jul. 2016.

REITHERMAN, W. [...] Mogli - O Menino Lobo (1967). Duração: 1 h 18 min. Cor: Colorido. Formato negativo: $35 \mathrm{~mm}$. Lançamento: 18 de Outubro de 1967. País: USA. 
RICHARD, V. Norman McLaren, manipulator of movement: The National Film Board Years, 1947-1967. Newark: University of Delaware, 1982. 128p. RUSSET, R.; STARR, C. Experimental animation: Origins of a new art. Newtons: Da Capo Press, 1988. 224p.

SANTOS, V. Tubarão baleia. Escola Kids. Disponivel em: <http://escolakids.uol.com.br/tubaraobaleia.htm>. Acesso em: 01dez. 2016. SANTOS, J. N.; SOUZA, C. F. S.; GEBARA, M. J. F. O filme de animação como recurso didático nas aulas de Ciências. Colloquium Humanarum, Presidente Prudente (SP), v. 12, n. Especial, p. 1363-1370. 2015.

SANTOS, M. S.; RODRIGUES, M. L. Análise do discurso dos personagens do filme Procurando Nemo segundo a inclusão. Discursividade Web Revista, Dourados (Mato Grosso do sul), n. 14, p.1-27. Julho de 2014.

SANTOS, C. R. M.; SILVA, P. R. Q. A utilização do lúdico para a aprendizagem do conteúdo de genética. Universitas Humanas, Brasília, v. 8, n. 2, p. 119-144, jul./dez. 2011.

SANTOS, S. P. S. A ciência e o cientista através da janela mágica. Estudo de caso com o filme "Sonhos Tropicais". Dissertação (Mestrado em Ensino em Biociências e Saúde) - Instituto Oswaldo Cruz, Rio de Janeiro, 2007. 188p. SOARES, B. C.; VIEIRA, B. M.; FONSECA, L. C. S. Procurando Nemo: o uso da animação para o ensino de ciências. Revista de Ensino de Biologia da Associação Brasileira de Ensino de Biologia (SBEnBio), Niterói (RJ), v. 7, p. 936-948, 2014.

SOBRINHO, R. S. A importância do ensino da biologia para o cotidiano. 2009. 40 p. Trabalho de Conclusão de Curso (Graduação em Biologia) - Faculdade Integrada da Grande Fortaleza, Fortaleza, 2009.

SOUZA, P. H. R.; MATTA, R. R.; MONERAT, C. A. A.; ROCHA, M.

B.; BARROS, M. D. M. O uso do cinema no ensino de ciências: uma proposta a partir do filme 'Tá chovendo hambúrguer'. Revista de Ensino de Biologia da Associação Brasileira de Ensino de Biologia (SBEnBIO), Niterói (RJ), v. 9, p. 688-699, 2016.

SOUZA, L. C.; JESUS, T. R.; ANDRADE, J. G.; BARROS, M. D. M. Trazendo o cinema para a sala de aula: a utilização do filme 'Amazônia em chamas' como estratégia de ensino. Revista de Ensino de Biologia da Associação Brasileira de Ensino de Biologia (SBEnBio), Niterói (RJ), v. 7, p. 5325-5336, 2014.

STANTON, A.; MacLANE, A. Procurando Nemo (2003). Duração: 1 h $37 \mathrm{~min}$. Cor: Colorido. Lançamento: 30 de Maio de 2003. País: USA.

STANTON, A.; UNKRICH, L. Procurando Dory (2016). Duração: 1 h 40 min. Cor: Colorido. Formato negativo: Digital. Lançamento: 8 de Junho de 2016. País: USA.

THOMAS, F.; JOHNSTON, O. The illusion of life: Disney animation. New York: Hyperion, 1995. 576p.

THOMAS, B. Walt Disney: O mago da tela. São Paulo: Melhoramentos, 1969. $174 \mathrm{p}$.

TROUSDALE, G.; WISE, K. A Bela e a Fera (1991). Duração: 1 h 24 min. Cor: Colorido. Formato negativo: 35 mm. Lançamento: 29 de Setembro de 1991. País: USA. 
VIEIRA, C. Cassiopéia (1996). Duração: 1 h 20 min. Cor: Colorido.

Lançamento: 1996. País: BRAZIL.

WEDGE, C.; SALDANHA, C. A Era do Gelo (2002). Duração: 1 h 43 min. Cor: Colorido. Formato negativo: Digital. Lançamento: 12 de março de 2002. País: USA. 